\title{
Synthesis and evaluation of mutual prodrugs of isoniazid, $p$-amino salicylic acid and ethambutol
}

\author{
Jyoti Rawat, Prateek K. Jain, V. Ravichandran, and R. K. Agrawal* \\ Pharmaceutical Chemistry Research Laboratory, Department of Pharmaceutical Sciences, \\ Dr. H. S. Gour Vishwavidyalaya, Sagar, (M.P), 470 003, India \\ E-mail: dragrawal2001@yahoo.co.in
}

\begin{abstract}
Ethambutol (EB), isoniazid (INH) and p-amino salicylic acid (PAS) are potent antitubercular agents having various side effects due to formation of toxic metabolites. The present study aims towards prevention of these side effects through mutual prodrug formation. Mutual prodrugs of EB with PAS (PE), PAS with PAS (PP) and INH with PAS (PI) were synthesized and characterized. Hydrolytic and absorption studies were performed in SGF (synthetic gastric fluid) and SIF (synthetic intestinal fluid). In vivo studies were also performed to confirm the release profile of the synthesized prodrugs. Formation of imide and ester functionalities was confirmed by IR spectra. In vitro hydrolysis studies in SGF and SIF reveal that these mutual prodrug conjugates do not hydrolyze appreciably and are absorbed unhydrolyzed. In vivo studies showed greater serum concentrations of EB, PAS and INH than their concentrations when given alone and isoniazid concentrations were greater except for PP. Peak plasma levels were attained after 3 $\mathrm{h}$ but these levels were reduced 0.6 times. Thus, mutual prodrugs PI and PE significantly eliminate the problem of fast metabolism, toxicity and local irritation and reduction of therapeutic doses. In the case of PP only local irritation could be avoided.
\end{abstract}

Keywords: Prodrugs, ethambutol, isoniazid, and $p$-amino salicylic acid

\section{Introduction}

Tuberculosis is one of the most widespread diseases in the world, particularly in India, and can be deadly in patients with AIDS worldwide. Therefore, chemoprophylaxis is given to HIV positive subjects. ${ }^{1}$ Antitubercular therapy is given for a long time, 3 months to 9 months, depending on the state of infection. It involves combination therapy because these drugs show better therapeutic results and the mycobacterium does not evolve resistance to one drug. Combination therapy incorporates 4-aminosalicylic acid (PAS), isoniazid (INH), ethambutol (EB) along with rifampicin, which is marketed in combination dosage form. In PAS, the free 
acidic carboxylic group is responsible for the gastrointestinal irritation and is extensively metabolized by acetylation of the amino group and conjugation with glucuronic acid and glycine at the carbonyl group. $\mathrm{T}_{1 / 2}$ for the metabolism of the drug is one hour, therefore, a large dose is given to maintain a minimum effective level of the PAS. INH is readily absorbed on oral administration. It is extensively metabolized to inactive metabolites (diacetylhydrazide, acetylhydrazide, $N$-acetylisoniazide and hydrazine). ${ }^{2}$ The major metabolite is $N$-acetylisoniazide. The enzyme, $\mathrm{N}$-acetyltransferase, is responsible for INH metabolism and is located in the liver and small intestine. PAS, when co-administered with $\mathrm{INH}$, is found to reduce the acetylation of $\mathrm{INH}$, itself being the substrate for acetylation, thus it increases the plasma level of INH. EB is a water-soluble, bacteriostatic agent which is readily absorbed (75-80\%) following oral administration. Most of the administered EB is excreted unchanged, with not more than 15\% appearing in urine in oxidized form of aldehyde or carboxylic acid. ${ }^{3,4}$

Substitution at the 2-hydroxy group or removal of the amino group of PAS abolishes the antitubercular activity, therefore various prodrugs were synthesized in the past, including macromolecular prodrugs, ${ }^{5-8}$ amides and ion pair complex. ${ }^{9-11}$ However, formations of mutual or chimera prodrugs have never been tried before. As in the case of NSAIDs, mutual prodrugs have been beneficial in reducing gastrointestinal irritation. ${ }^{12}$

Therefore, the synthesis of mutual prodrugs was conceptualized with the aim: (i) Reduction of gastro-intestinal toxicity of PAS. (ii) Reduction of intestinal acetylation of Isoniazid. (iii) Increase in duration of action. And (iv) Decrease of dose of drugs. Thus, the above-mentioned drugs (INH and EB) were conjugated with PAS through amidation and esterification, respectively, to prevent catabolism of INH through acetylation and also to reduce the gastric acidity caused by PAS through esterification of its carboxylic group with an alcohol group in EB. Furthermore, esterification will prevent the catabolism of EB via bio-oxidation of its free alcohol group. Similarly, INH and PAS can be linked through an amide bond and PAS can be dimerized, taking advantage of its having amino, phenolic and carboxylic acid groups within the same molecule. After the absorption, the expectation is that amidase and esterases will cleave these conjugates to the parent drugs, i.e., INH, PAS or EB. Thus, the present study aims towards the prevention of the local irritation caused by PAS, local catabolism of PAS and INH and biooxidation of EB through a mutual prodrug approach involving the preparation of mutual prodrug conjugates.

\section{Results and Discussion}

The physical properties and results of elemental analysis of synthesized mutual prodrugs, PI, PE and PP are shown in Table 1. Observed characteristic absorption IR spectral data and UV $\lambda_{\max }$ are shown in Table 2. In mutual prodrug PI, the free -O-H (str) due to the carboxylic group, which should be in the form of a series of broad bands between $\left(3500-2500 \mathrm{~cm}^{-1}\right)$, is not observable, confirming the formation of the PI prodrug (amide bond). In mutual prodrug PP, an 
amide bond is formed which is confirmed by secondary amide $(\mathrm{O}=\mathrm{C}-\mathrm{NH})$ bonds in the IR spectrum at 1558 and $1512 \mathrm{~cm}^{-1}$. In mutual prodrug $\mathrm{PE}$, the $\mathrm{C}=\mathrm{O}$ (str) vibration of the carboxylic group of PAS has been shifted upward (1628 to $1735 \mathrm{~cm}^{-1}$ ) and the C-O (str) has moved downward (1297 to $1256 \mathrm{~cm}^{-1}$ ) due to esterification with the hydroxyl group of EB. ${ }^{13,14}$ Thus, the mutual prodrugs so synthesized comply with the expected structures. FAB mass spectra, $1 \mathrm{H}$ NMR spectra (DMSO- $\mathrm{d}_{6}$ ) and elemental (nitrogen) analyses also confirm the proposed structures, and are shown in Tables 1 and 2.

Table 1. Physical properties of prodrugs

\begin{tabular}{|c|c|c|c|c|c|c|c|c|}
\hline \multirow{2}{*}{$\begin{array}{l}\text { Mutual } \\
\text { prodrugs }\end{array}$} & \multirow{2}{*}{$\begin{array}{l}\text { Molcular } \\
\text { Formula }\end{array}$} & \multirow{2}{*}{$\begin{array}{l}\text { Molecular } \\
\text { Weight }\end{array}$} & \multicolumn{2}{|c|}{$\%$ Nitrogen } & \multirow{2}{*}{$\begin{array}{l}\text { Yield } \\
(\mathrm{g})\end{array}$} & \multirow{2}{*}{$\begin{array}{l}\% \\
\text { Yield }\end{array}$} & \multirow[t]{2}{*}{ Odor } & \multirow{2}{*}{$\begin{array}{l}\text { Melting } \\
\text { point } \\
\left({ }^{\circ} \mathrm{C}\right)\end{array}$} \\
\hline & & & Found & Calcd. & & & & \\
\hline PI & $\mathrm{C}_{13} \mathrm{H}_{12} \mathrm{~N}_{4} \mathrm{O}_{3}$ & 272 & 20.58 & 20.63 & 10.25 & $68 \%$ & Odorless & $220-222$ \\
\hline $\mathrm{PE}$ & $\mathrm{C}_{19} \mathrm{H}_{33} \mathrm{~N}_{3} \mathrm{O}_{4}$ & 367 & 11.43 & 11.68 & 4.16 & $56 \%$ & Odorless & $296-300$ \\
\hline $\mathrm{PP}$ & $\mathrm{C}_{14} \mathrm{H}_{12} \mathrm{~N}_{2} \mathrm{O}_{5}$ & 288 & 9.27 & 9.43 & 7.45 & $45 \%$ & Odorless & $326-328$ \\
\hline
\end{tabular}

Table 2. Spectral characterization of synthesized mutual prodrugs

\begin{tabular}{|c|c|c|c|c|}
\hline Prodrugs with code & $\begin{array}{l}\text { UV } \\
\left(\lambda_{\max }\right. \\
\text { in } \mathrm{nm})\end{array}$ & $\begin{array}{l}\text { Mass } \\
\text { spectral } \\
\text { data }(\mathrm{m} / \mathrm{z})\end{array}$ & $\begin{array}{l}\text { IR Spectral data } \\
\text { Wave number } \\
\left(\mathrm{cm}^{-1}\right)\end{array}$ & $\begin{array}{l}\text { 1H NMR Spectral } \\
\text { Data }[\delta(\mathrm{ppm})]\end{array}$ \\
\hline $\begin{array}{l}\text { Para-aminosalicylic acid } \\
\text { with isoniazid (PI) }\end{array}$ & 276 & 272 & $\begin{array}{lr}3392, & 1651, \\
1568, & 1511, \\
1338, & 1303, \\
1258, & 1200,774\end{array}$ & $\begin{array}{c}4.1\left(\mathrm{~s}, 2 \mathrm{H}, \mathrm{Ar}-\mathrm{NH}_{2}\right), \\
6.1-7.5(\mathrm{~m}, 3 \mathrm{H}, \mathrm{Ar}-\mathrm{H}), \\
7.9(\mathrm{~d}, 2 \mathrm{H}, \text { pyridyl }), \\
8.1(\mathrm{~s}, 2 \mathrm{H}, 2 \mathrm{C} \text { CO-NH), } \\
9.2(\mathrm{~s}, 2 \mathrm{H},-\mathrm{CH}-\mathrm{N} \text { pyridyl })\end{array}$ \\
\hline $\begin{array}{l}\text { Para-aminosalicylic acid } \\
\text { with para-aminosalicylic } \\
\text { acid (PP) }\end{array}$ & 301 & 368 & $\begin{array}{lr}3360, & 1656, \\
1598, & 1556, \\
1512, & 1499, \\
1472, & 1381, \\
1338, & 1256- \\
1156,796-740 .\end{array}$ & $\begin{array}{c}4.3\left(\mathrm{~s}, 2 \mathrm{H}, \mathrm{Ar}-\mathrm{NH}_{2}\right), \\
6.1-7.6(\mathrm{~m}, 6 \mathrm{H}, \mathrm{Ar}-\mathrm{H}), \\
7.9(\mathrm{~d}, 2 \mathrm{H}, \mathrm{pyridyl}), \\
8.2(\mathrm{~s}, 2 \mathrm{H}, 2 \times \mathrm{CO}-\mathrm{NH}), \\
11(\mathrm{~s}, 1 \mathrm{H},-\mathrm{COOH})\end{array}$ \\
\hline $\begin{array}{l}\text { Para-aminosalicylic acid } \\
\text { with ethambutol (PE) }\end{array}$ & 316 & 288 & $\begin{array}{l}3620, \quad 3360- \\
3334, \quad 1735, \\
1656, \quad 1598, \\
1501-1492, \\
1467, \quad 1338, \\
1256,1082,794, \\
774,706-668 .\end{array}$ & $\begin{array}{l}0.9\left(\mathrm{t}, 6 \mathrm{H}, 2 \times \mathrm{CH}_{3}\right), \\
1.4\left(\mathrm{~m}, 4 \mathrm{H}, 2 \times \mathrm{CH}_{2}\right), \\
2.7\left(\mathrm{t}, 4 \mathrm{H}, 2 \mathrm{x}-\mathrm{CH}_{2}-\mathrm{NH}\right), \\
4.0\left(\mathrm{~s}, 2 \mathrm{H}, \mathrm{Ar}-\mathrm{NH}_{2}\right), \\
4.2\left(\mathrm{t}, 2 \mathrm{H},-\mathrm{O}-\mathrm{CH}_{2}\right), \\
6.1-7.6(\mathrm{~m}, 3 \mathrm{H}, \mathrm{Ar}-\mathrm{H})\end{array}$ \\
\hline
\end{tabular}




\section{In vitro hydrolysis studies}

In SGF in vitro hydrolysis studies, the order of drug release was PE (2.63\%): PI (4.2\%) and PP $(9.32 \%)$. In SIF in vitro hydrolysis and absorption studies, the following order of drug release was observed: PE (12.2\%) PI (12.63\%) \& PP (22.7\%). The hydrolysis patterns for the synthesized prodrugs are shown in Figures $1-6$. The in vitro hydrolysis and absorption studies in simulated (SGF) and SIF reveal that these mutual prodrug conjugates do not hydrolyze appreciably and are absorbed unhydrolyzed. Thus, local irritation and local acetylation of PAS, local acetylation of $\mathrm{NH}$ and bio-oxidation of $\mathrm{EB}$ after absorption, are prevented through the mutual prodrug approach.

\section{In vivo studies}

An in vivo study was conducted to determine the plasma concentration drug time profile using UV spectrophotometric determination. In this study all mutual prodrugs and individual drugs were administered orally to rats and after $1.5 \mathrm{~h}$ intervals drug concentrations were determined in serum. In prodrug (PI), serum concentrations of PAS and INH were determined. The PAS concentration was 18.4 times greater than its concentration when given alone and the isoniazid concentration was 1.8 times greater than its concentration when given alone. Peak plasma concentrations were attained after $3 \mathrm{~h}$ interval. The patterns of periodic serum levels for the synthesized prodrugs are shown in Figures 7-9. In the case of prodrug (PP), peak plasma concentration was attained after $3 \mathrm{~h}$ but the drug serum level was reduced 0.6 times. This could be due to acetylation of its amino group whereas in the case of PI, after hydrolysis in serum, the amino group of isoniazid was competitively sacrificed and, thus, PAS concentration was increased. In the case of prodrug (PE), the peak plasma concentration of PAS was attained after $4.5 \mathrm{~h}$ and maintained up to $6 \mathrm{~h}$. The concentration was 4.6 times greater than its concentration when given alone.

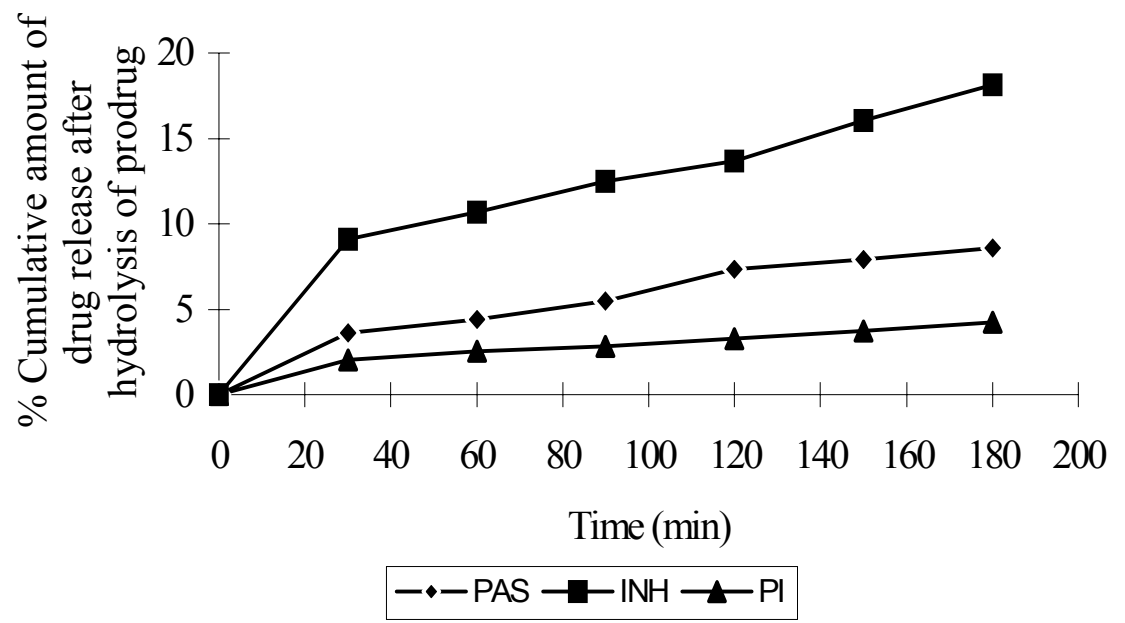

Figure 1. In vitro hydrolysis of prodrug PI in SGF. 


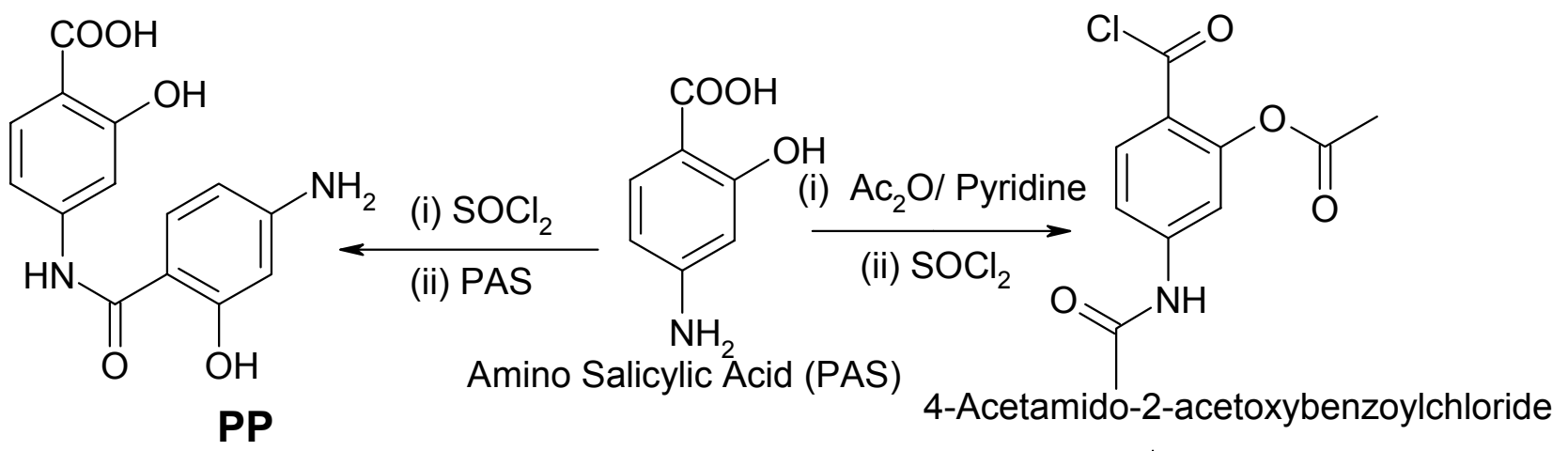<smiles>[Y]OC(C)=O</smiles>

Scheme 1. Synthesis of mutual prodrug of aminosalicylic acid, isoniazid and ethambutol. 


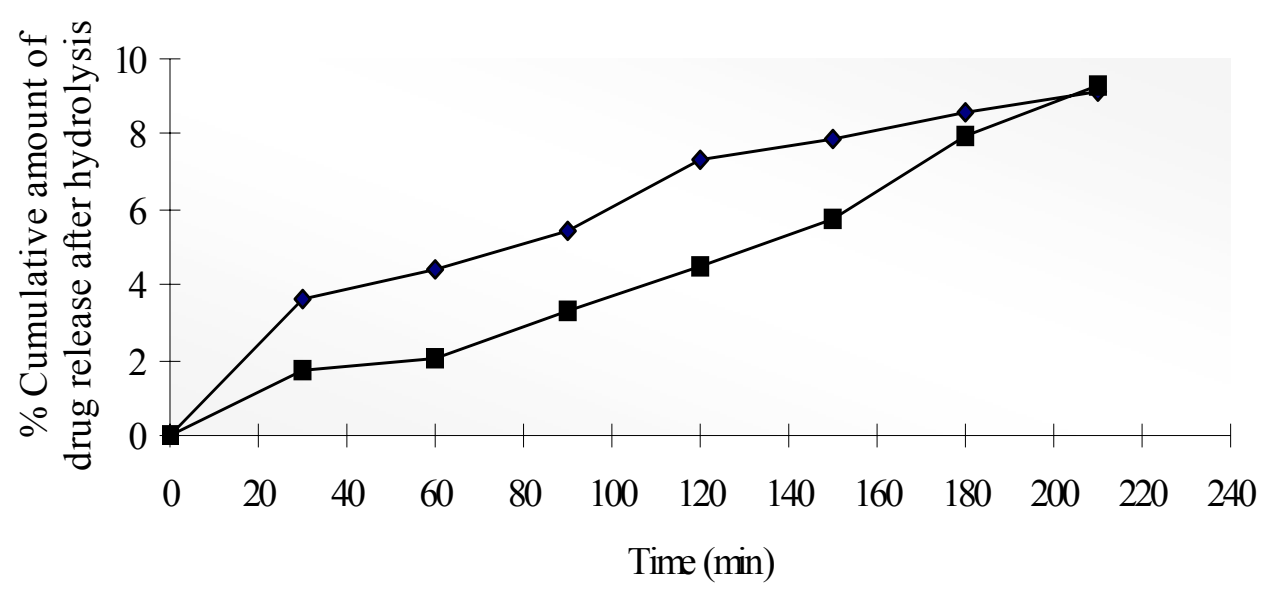

$\multimap$ PAS $\rightarrow$-PP

Figure 2. In vitro hydrolysis study of prodrug PP in SGF.

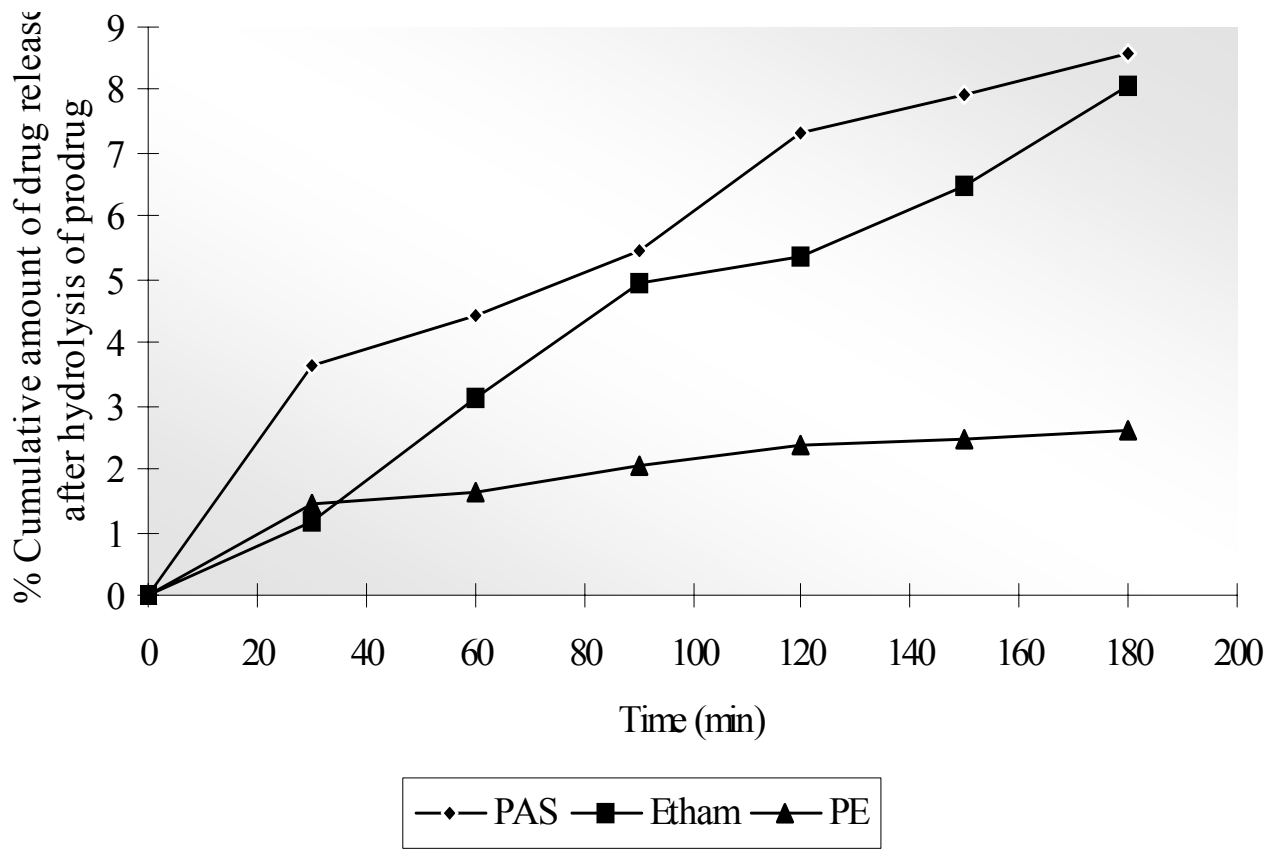

Figure 3. In vitro hydrolysis of prodrug PE in SGF 


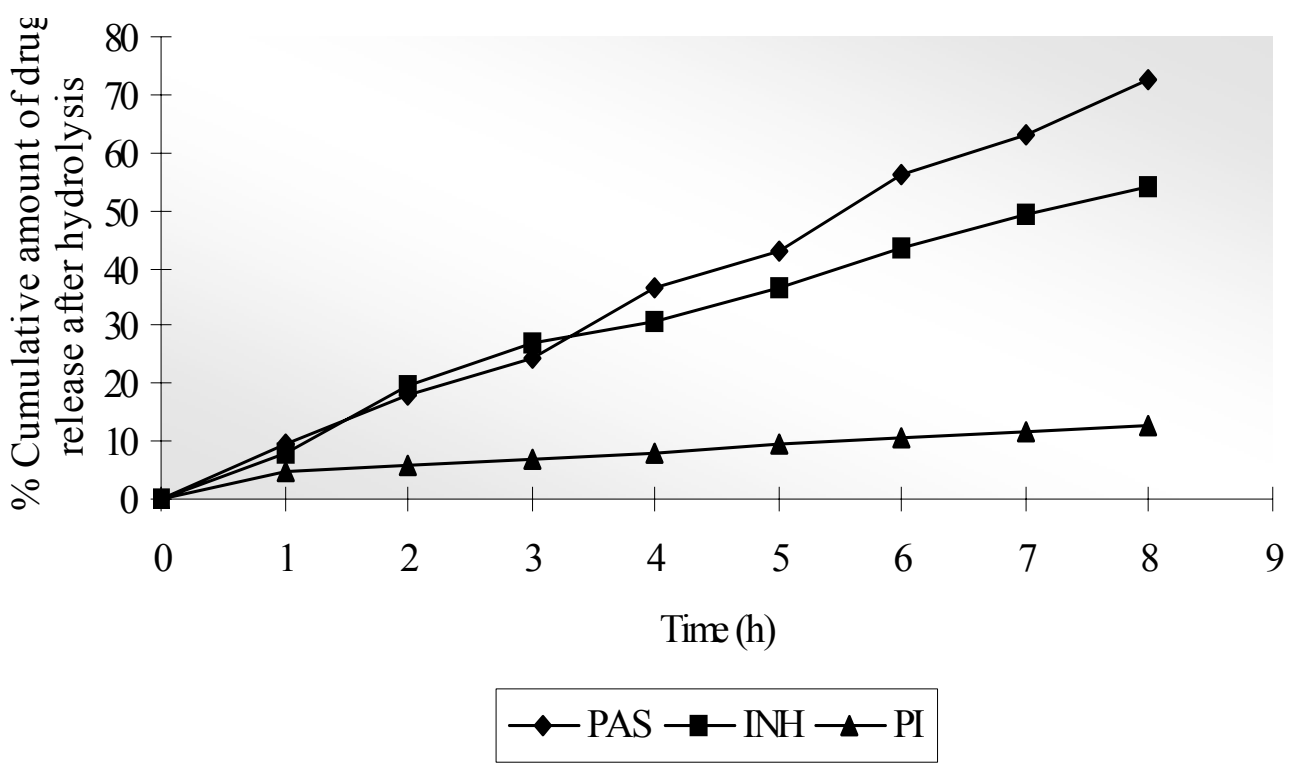

Figure 4. In vitro hydrolysis study of prodrug PI in SIF

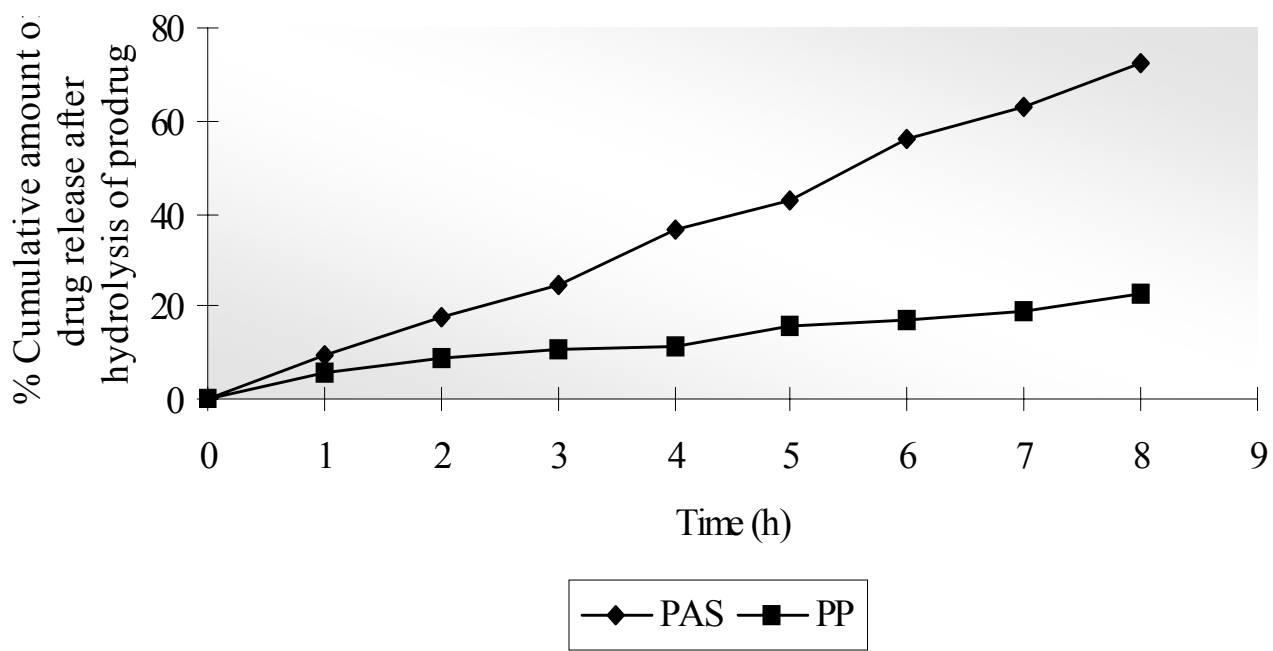

Figure 5. In vitro hydrolysis study of prodrug PP in SIF. 


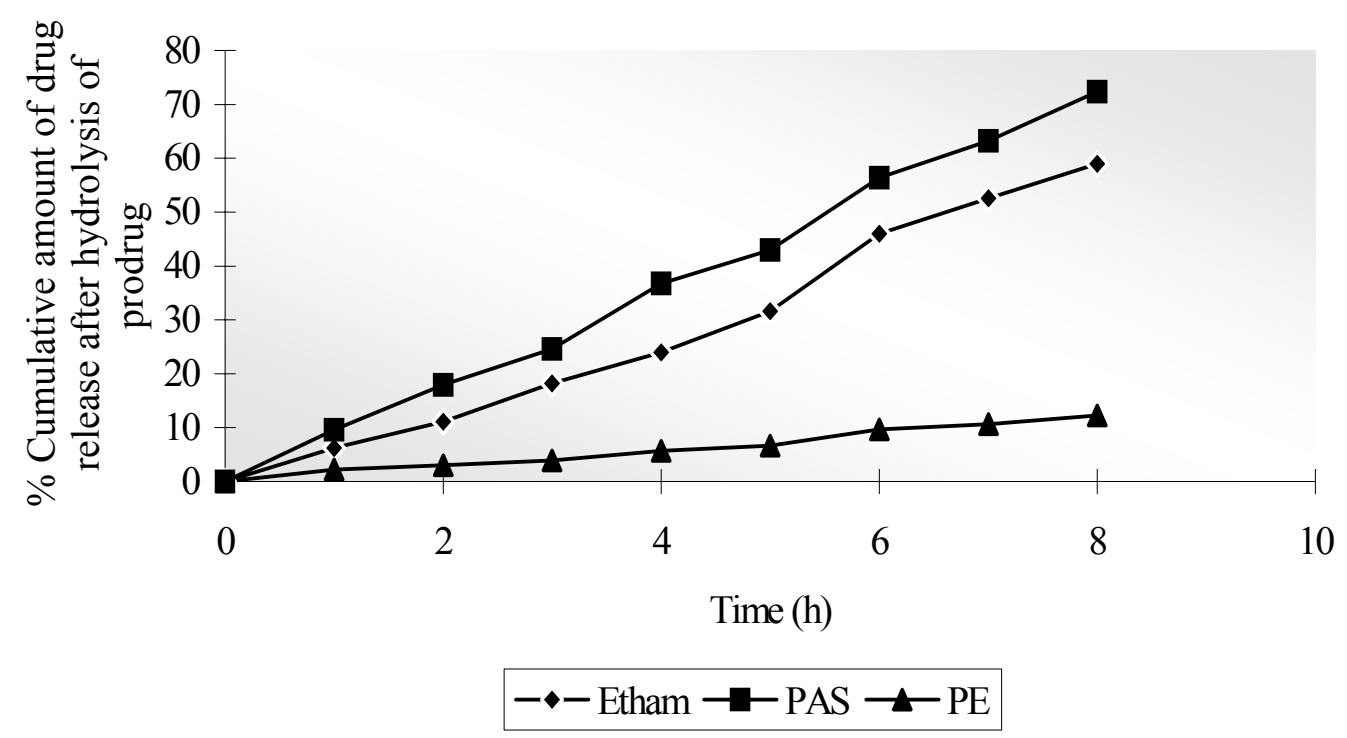

Figure 6. In vitro hydrolysis study of prodrug PE in SIF.

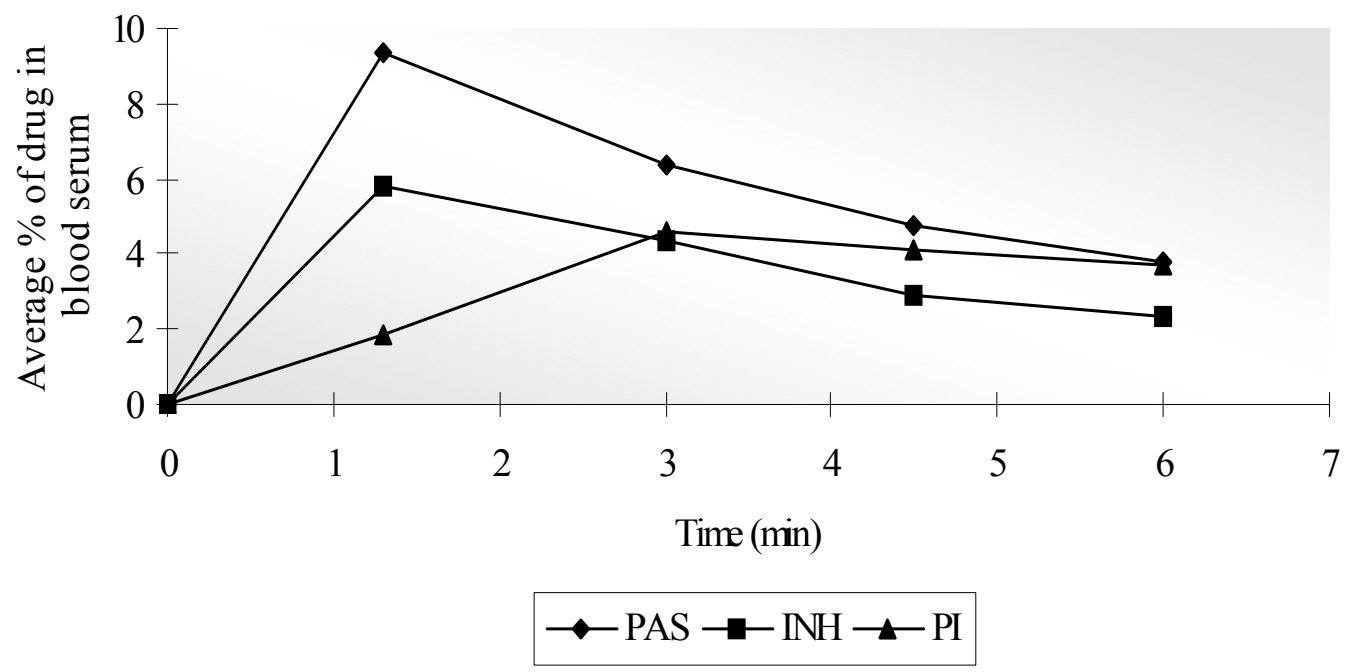

Figure 7. Average drug blood level concentration. 


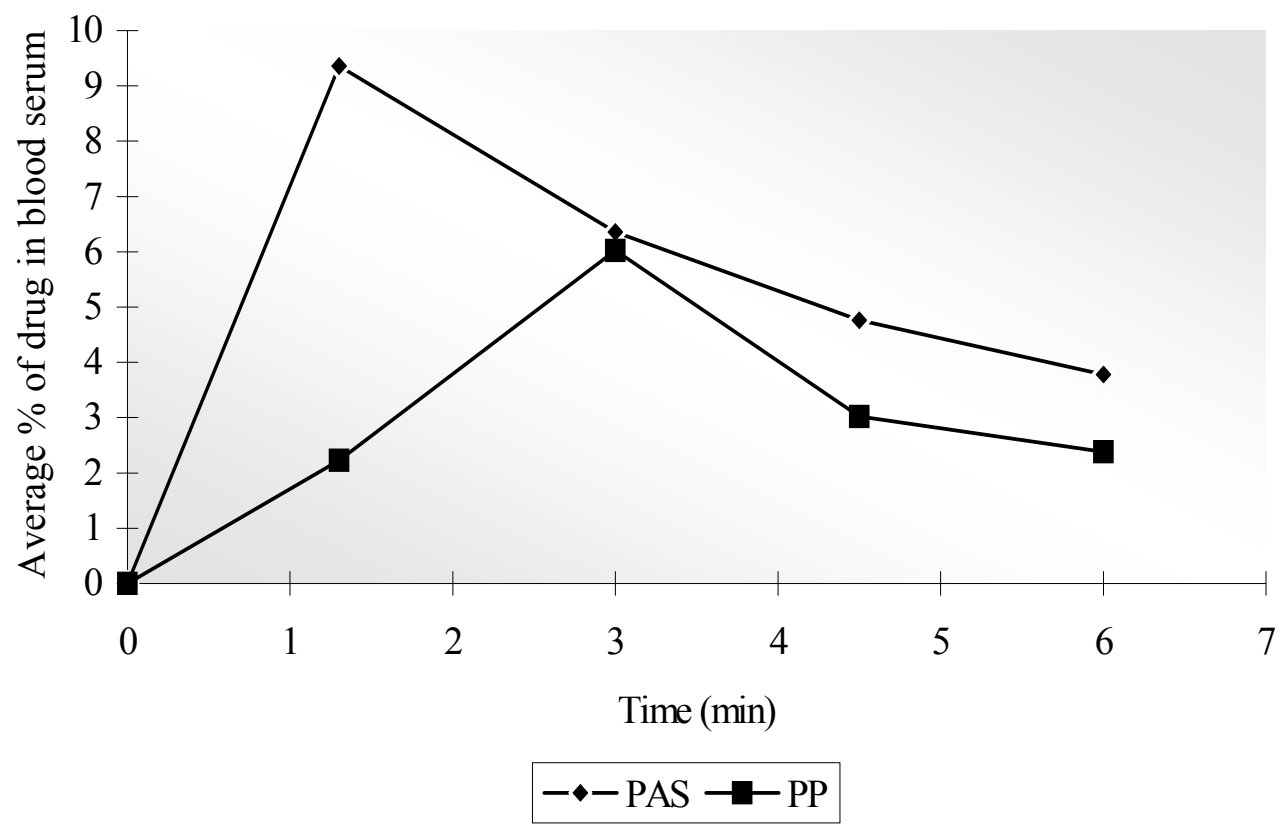

Figure 8. Average drug blood level concentration.

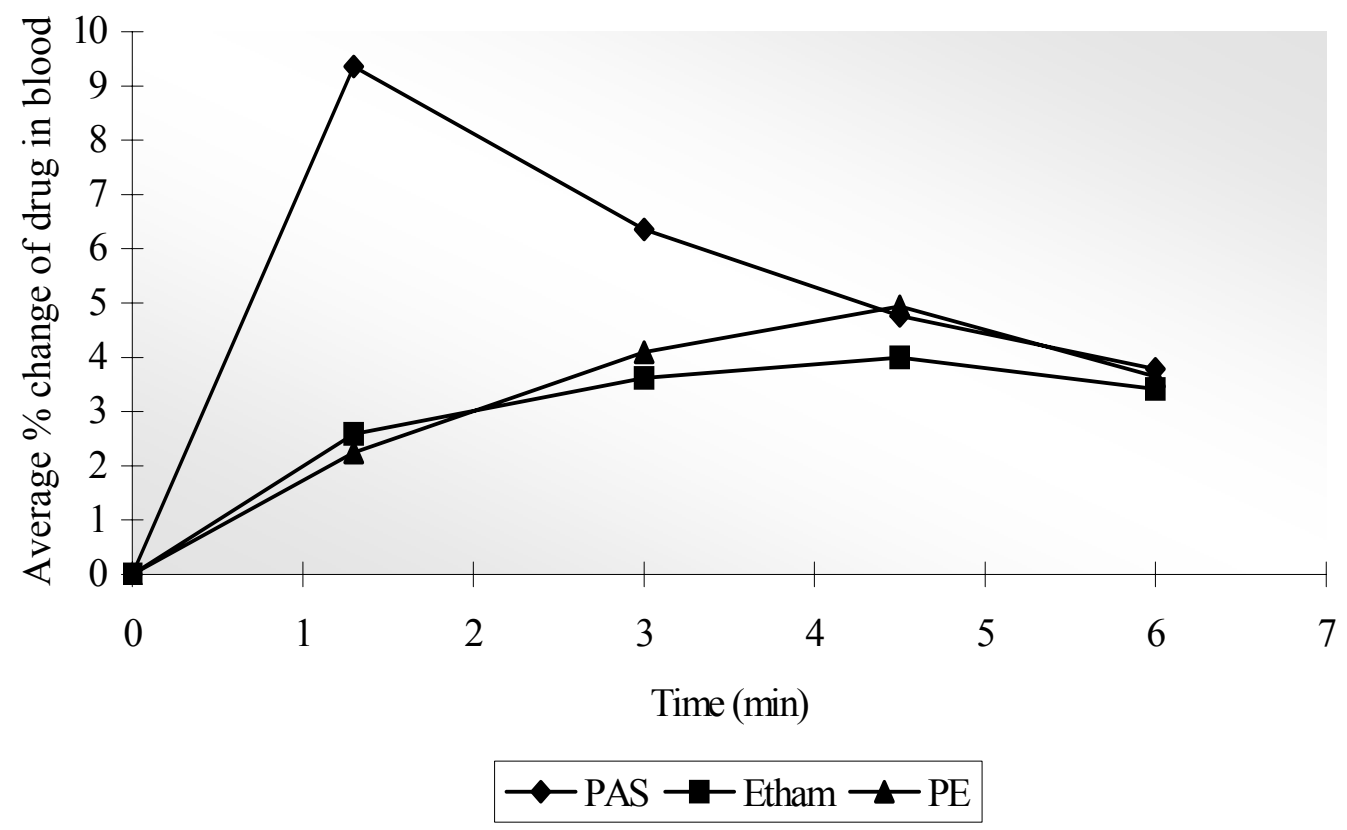

Figure 9. Average drug blood level concentration of Prodrug PE. 


\section{Conclusions}

In vitro hydrolysis and absorption studies in SGF and SIF reveal that these mutual prodrug conjugates do not hydrolyze appreciably and are absorbed unhydrolyzed. In vivo studies showed greater serum concentrations of EB, PAS and INH than their concentrations when given alone. It can be concluded that the use of the mutual prodrug approach eliminates significantly the problem of catabolism by acetylation in GIT and toxicity of PAS and INH.

\section{Experimental Section}

General Procedures. PAS was procured from M/S Himedia Ltd., Mumbai, EB was obtained as a gift from M/S Alkem Pharmaceuticals Ltd. Mumbai and INH was procured from M/S Sisco Research Organizations Ltd. Other chemicals used in the study were of analytical/ spectroscopic grades.

\section{Synthesis of the mutual prodrugs}

Synthesis of mutual prodrugs (PI and PP) was carried out using the general methods adopted for syntheses of peptides and proteins through amidation with PAS. ${ }^{15,16}$ Synthesis of the mutual prodrug (PE) was carried out through esterification with PAS. In the syntheses of PI and PE the protection of amino and phenolic group was essential to avoid the internal polymerization or formation of intra-molecular esters or amides. Protection of the amino and phenolic groups was done by acetylation of these groups. Thereafter, an acyl chloride was formed which was reacted with EB and INH to form the corresponding ester (PE) or amide (PA). Synthesis of PP was effected by forming an acyl chloride of PAS and reacting it with PAS to form PP.

Synthesis of 4-acetylamino-2-acetoxybenzoic acid. PAS (5 g) was placed into a $250 \mathrm{ml}$ round bottom flask, $50 \mathrm{ml}$ of acetic anhydride and $50 \mathrm{ml}$ of pyridine were added to it and the resultant solution was refluxed for $1 \mathrm{~h}$ on water bath. The refluxed material was added to $200 \mathrm{ml}$ of icecold water, stirred vigorously for $1 \mathrm{~h}$ (using a magnetic stirrer), cooled and allowed to stand until the diacetylated derivative was crystallized. The diacetylated product was collected by filtration, washed well with water and dried at $105^{\circ} \mathrm{C}$ for $1 \mathrm{~h}$. Recrystallisation was done from hot water (about $75 \mathrm{ml}$ ). The diacetylated derivative so obtained was taken for further synthesis.

Synthesis of 4-acetylamino-2-acetoxybenzoyl chloride. 4-Acetyl amino-2-acetoxybenzoic acid $(9.5 \mathrm{~g})$ was taken in a $250 \mathrm{ml}$ two necked round bottom flask, $40 \mathrm{ml}$ pyridine was added to it and the mixture was refluxed gently for $3 \mathrm{~h}$. along with dropwise addition of $25 \mathrm{ml}$ of redistilled thionyl chloride through a dropping funnel. The excess of thionyl chloride was distilled off. The residue in the flask was 4-acetyl amino-2-acetoxybenzoyl chloride, which was used without further purification.

Synthesis of 4-acetyl amino-2- acetoxybenzoyl conjugates 
Amide conjugate. INH (7.6 g) was placed in a conical flask containing $45 \mathrm{ml}$ of pyridine and 4acetyl amino-2-acetoxybenzoyl chloride (14.5 g). The mixture was refluxed for $1 \mathrm{~h}$ at $100^{\circ} \mathrm{C}$ on a water bath. After cooling the mixture it was set aside. After $24 \mathrm{~h}$ it was poured into $200 \mathrm{~g}$ crushed ice and the resultant compound (the diacetyl conjugate of PI) was obtained as a precipitate, which was filtered, washed with water and drained well. The crude diacetyl conjugate of PI was then recrystallized from rectified alcohol.

\section{Ester conjugate}

Ethambutol hydrochloride (EB HCl; $14.7 \mathrm{~g}$ ) was placed in a conical flask containing $45 \mathrm{ml}$ of pyridine. 4-Acetylamino-2-acetoxybenzoyl chloride (18.0 g) was added and the mixture was refluxed for $1 \mathrm{~h}$ on a water bath and allowed to cool. After $24 \mathrm{~h}$ it was added to $200 \mathrm{~g}$ crushed ice and the resultant compound (the diacetyl conjugate of $\mathrm{PE}$ ) was obtained as a precipitate, which was filtered, washed with water and drained well. The crude diacetyl conjugate of PE was then recrystallized from rectified alcohol.

\section{Removal of the acetyl group from the conjugates}

The diacetylated prodrug conjugates $(3 \mathrm{~g}$ ) were hydrolyzed with $100 \mathrm{ml}$ of $15 \%$ ethanolic hydrochloric acid for $30 \mathrm{~min}$. The excess of acid was neutralized with $15 \%$ ammonium hydroxide solution. Recrystallisation was done from $50 \%$ aqueous ethanol.

\section{Synthesis of $\mathbf{N}$-2-(hydroxy-4-aminobenzoyl) -2-hydroxy-4-aminobenzamide (PP)}

2-Hydroxy-4-aminobenzoyl chloride was synthesized by a similar method to that described earlier for the synthesis of 4-acetyl amino-2-acetoxybenzoyl chloride by taking $5 \mathrm{~g}$ of PAS in place of $9.5 \mathrm{~g}$ of 4-acetyl amino-2-acetoxybenzoic acid. The resultant 2-hydroxy-4aminobenzoyl chloride residue was treated with PAS $(5 \mathrm{~g})$ similarly to the process described in the synthesis of the 4-acetyl amino-2- acetoxybenzoyl amide conjugate. Recrystallisation was performed from rectified spirit.

\section{Characterization of synthesized mutual prodrugs}

Physical properties for each synthesized prodrug, viz., yields, color, odor, solubility and m.p., were noted. For determination of solubility, approximately $5 \mathrm{mg}$ of compound was dissolved in 5 $\mathrm{ml}$ of each solvent at $37 \pm 1^{0} \mathrm{C}$ in a glass test tube. The solvents used were $0.1 \mathrm{~N} \mathrm{NaOH}$, ethanol, methanol, ether, ethyl acetate, $0.1 \mathrm{~N} \mathrm{HCl}, \mathrm{CHCl}_{3}, \mathrm{CCl}_{4}$, acetone, DMF, acetonitrile and water. The test tubes were gently shaken and the solubility of the prodrug was noted in each individual solvent. Physical properties are shown in Table 1. All of the synthesized prodrugs were tested qualitatively for the representative group tests described by Vogel and Agrawal. ${ }^{17,18}$ Quantitative elemental analysis for \% nitrogen was performed for the synthesized prodrugs using a nitrogen analyzer (Heraeus Carlo Erba 1108) (CDRI, Lucknow, India) and the expected and obtained values are given in Table 1. The mass spectra were determined on Jeol SX 102 mass spectrometer (Jeol SX102-FAB) (CDRI, Lucknow, India), 1H NMR spectra (in DMSO-d 6 ) were recorded at $300 \mathrm{MHZ}$ on a Bruker NMR spectrophotometer and the results are shown in Table 2.

Prodrug solutions $(20 \mu \mathrm{g} / \mathrm{ml})$ were prepared in PBS pH 7.4. Prodrugs solutions were scanned between 200-400 $\mathrm{nm}$ and observations were recorded using a Schimadzu $1601 \mathrm{UV}$ 
Spectrophotometer. The wavelengths of maximum absorption $\left(\lambda_{\max }\right)$ are shown in Table 2 . IR spectral data are shown in Table 2.

\section{In vitro hydrolysis study}

The in vitro hydrolysis of the synthesized compounds was carried out using diffusion through fundus part of stomach and through intestine wall.

\section{Methods of quantitative analyses}

The rates of hydrolysis of the drugs were determined using simulated SGF and SIF. These studies were performed using the stomach and intestinal sac method in rat stomach and intestine at $37 \pm 0.5^{\circ} \mathrm{C}$ at $\mathrm{pH} 1.2$ (SGF) and $\mathrm{pH} 7.4$ (SIF). After the development of methods, the in vitro hydrolytic and absorption studies were conducted. For simultaneous analyses of PAS and INH, as released by hydrolysis of PI, standard curves were prepared in PBS, SGF and SIF and the equation was developed for simultaneous estimation of PAS and INH. The absorbance $\lambda_{\max }$ of PAS and INH were $298 \mathrm{~nm}$ and $265 \mathrm{~nm}$, respectively. The equation used for the present study, after measuring absorbance at $265 \mathrm{~nm}$, was: $\mathrm{A}_{265}=0.0797 \mathrm{C}_{1}+0.0313 \mathrm{C}_{2}$

In the present equation, $\mathrm{A}_{265}$ is absorbance of the sample containing PAS and INH after hydrolysis and, as one mol of prodrug will give one mol each of the drugs PAS and INH, therefore, the molar concentration of these drugs will be the same, which are expressed by $\mathrm{C}_{1}$ and $\mathrm{C}_{2}$ respectively. For the analyses of $\mathrm{PE}$ for hydrolytic release of PAS and $\mathrm{EB}$, estimation of EB was done by charge transfer complex formation between EB and iodine as the basis for a sensitive spectrophotometric procedure for EB and its dosage forms. The solution exhibited blueshifted Iodine bands at 293 and $360 \mathrm{~nm}$, by UV spectrophotometer (Schimadzu, 1601) at 292.6 $\mathrm{nm}$, and the concentration of PAS was assumed to be of the similar molar value as $1 \mathrm{~mol}$ of prodrug will give $1 \mathrm{~mol}$ each of the drugs EB and PAS. For the analysis of PP, as the prodrug would be hydrolyzed into 2 mol of PAS, no special method was required.

\section{In vitro hydrolysis studies in SGF}

The pyloric end of the stomach was tightly bound with thread and $1 \mathrm{ml}$ drug solution (prepared in SGF) was injected into the stomach from the fundus part. This drug filled stomach was dipped into the beaker containing $100 \mathrm{ml}$ PBS pH 7.4 buffer solutions. The whole assembly was placed on a magnetic stirrer and maintained at $37 \pm 0.5^{\circ} \mathrm{C}$. After every $1 \mathrm{~h}$ interval, drug solution was taken out and replaced with $5 \mathrm{ml}$ PBS ( $\mathrm{pH}$ 7.4). The drug content was measured against a blank at $265 \mathrm{~nm}$ (in cases of PAS and INH) and EB using a Schimadzu, 1601 Spectrophotometer. The results are shown in Figures 1-3.

\section{In vitro hydrolysis studies in SIF}

The apparatus for the in vitro hydrolysis studies consisted of a beaker containing PBS having $\mathrm{pH}$ 7.4, a 2 inch piece of intestine was cut and washed with water then with PBS (7.4) buffer solution and both ends were tightly closed with the help of thread. The sac was filled with $1 \mathrm{ml}$ drug/prodrug solution by injection. The concentrations of drug samples were $10 \mathrm{mg} / \mathrm{ml}$ and these samples were prepared in SIF. This drug filled intestine was dipped into the beaker containing $100 \mathrm{ml}$ PBS pH 7.4 buffer solutions. The whole assembly was placed on a magnetic stirrer and maintained at $37 \pm 0.5^{\circ} \mathrm{C}$. After every $1 \mathrm{~h}$ interval, drug solution was taken out and replaced with 
$5 \mathrm{ml}$ of PBS pH 7.4. The drug content was measured against a blank reagent at $265 \mathrm{~nm}$ using a Schimadzu, 1601 Spectrophotometer. The results are shown in Figures 4-6.

\section{In vivo Studies}

In vivo studies were conducted using albino rats (Wistar rats) and the plasma concentration time profile of each drug was determined using a UV spectrophotometric determination. In this study, all mutual prodrugs and individual drugs were administered orally to rats and after $1.5 \mathrm{~h}$ intervals drug concentrations were determined in serum. The method used for such determination is as follows.

Albino rats (Wistar rats) were divided into seven groups having three rats in each group. One group was kept as a control. Three groups of animals were given plain drug solution prepared in PBS (pH 7.4): PAS, $100 \mathrm{mg} / \mathrm{kg}$ body weight, EB, $25 \mathrm{mg} / \mathrm{kg}$ body weight, and INH, $5 \mathrm{mg} / \mathrm{kg}$ body weight. Another three groups of animals were given synthesized compounds (mutual prodrugs) PI, $5 \mathrm{mg} / \mathrm{kg}$ body weight, PE, $25 \mathrm{mg} / \mathrm{kg}$ body weight and PP, $50 \mathrm{mg} / \mathrm{kg}$ body weight. Drug solutions were administered through the oral route with the help of a canula. After every $1.5 \mathrm{~h}$ interval, $0.2 \mathrm{ml}$ blood sample was collected. All blood samples were taken in micro centrifuge tubes containing potassium oxalate solution $(10 \% \mathrm{w} / \mathrm{v})$. The blood samples were centrifuged at $3000 \mathrm{rpm}$ for $15 \mathrm{~min}$. The supernatant (plasma) was deproteinized by adding acetonitrile ( $1 \mathrm{ml} / \mathrm{ml}$ of plasma). The samples were again centrifuged and $2 \mathrm{ml}$ of these supernatants was diluted to $10 \mathrm{ml}$ with PBS ( $\mathrm{pH}$ 7.4). One $\mathrm{ml}$ of this diluted blood serum was then made up to the mark $(10 \mathrm{ml})$ with PBS, then analyzed spectrophotometrically at $266 \mathrm{~nm}$ for drug content against a similarly treated blood sample of control rats after proper dilution. The observations were recorded (Figure 7-9). Drug samples were withdrawn at $1.5 \mathrm{~h}$ intervals.

\section{Acknowledgements}

One of the authors, Jyothi Rawat, is thankful to the University Grant Commission, New Delhi, India for providing financial assistance.

\section{References}

1. Edwards, P. Q. Bull. N.Y. Acad. Med.1977, 53, 526.

2. Kathleen, P.; Martindale: The Complete Drug Reference, $32^{\text {nd }}$ Edn.; Pharmaceutical Press: USA, 1999, p 151.

3. Byrd, R. B.; Horn, B. R.; Solomon, D. A.; Griggs, G. W. Chemoprophylaxis 1979, 241, 1239.

4. Miller, R. R.; Porter, J.; Greenblatt, D.J. Chest 1979, 75, 356.

5. Roseeuw, E.; Coessens, V.; Balazuc, A. M.; Lagranderie, M.; Domurado, D. Chemother. 2003, 47, 34. 
6. Silva, M.; Lara, A. S.; Leite, C. Q.; Ferreira, E. I. Arch. Pharm. 2001, 334, 189.

7. Giammona, G.; Giannola, L. I.; Carlisi, B.; Bajardi, M. L. Chem. Pharm. Bull. 1989, 37, 2245.

8. Giannola, L. I.; Giammona, G.; Alotta, R. Pharmazie 1992, 47, 423.

9. Peloquin, C. A.; James, G. T.; Craig, L. D.; Kim, M.; McCarthy, E. A.; Iseman, M. D. Pharmacotherapy 1994, 14, 415.

10. Aboul-Fadl, T.; Hassanin K. Pharmazie 1999, 54, 244.

11. Zhou, H.; Lengsfeld, C.; Claffey, D.J.; Ruth, J. A.; Manning, M. C. J. Pharm. Sci. 2002, 91, 1502 .

12. Streitweiser, A.; Heathcock, G.H. In Introduction to Organic Chemistry, $3^{\text {rd }}$ Edn.; Macmillan Publishing Company: New York, NY, 1989, p 947.

13. Bellamy, L. J. In The Infra-red Spectra of Complex Molecules, $3^{\text {rd }}$ Edn.; Chapman \& Hall: London, UK, 1975, p 231.

14. Higuchi, T. In Biopharmaceutics and Relevant Pharmacokinetics, Drug Intelligence Publication: Hamilton, 1991, p 111.

15. Norman, R. O. C.; Coxon, J. M. Principles of organic Synthesis, $3^{\text {rd }}$ Edn.; ELBS and Chapman \& Hall: London, UK, 1993, p 339.

16. Agrawal, O. P. In Practical Organic Chemistry, $20^{\text {th }}$ Edn.; Goel Publishing House: Meerut, India, 1993; p 40.

17. Vogel, A. I. Text Book of Practical Organic Chemistry, $4^{\text {th }}$ Edn.; ELBS and Chapman and Hall: London, 1978; pp 11-31.

18. Silverstein, R. M.; Webster, F. X. Spectrometric Identification of Organic Compounds, $6^{\text {th }}$ Edn.; John Wiley \& Sons, Inc.: New York, NY, 1998, p 71. 